\title{
Designing a Profit-Maximizing Product Line for Heterogeneous Market
}

\author{
Marija KUZMANOVIC, Milan MARTIC, Mirko VUJOSEVIC
}

\begin{abstract}
Designing product line is important marketing decision that affects the firm's overall performances and profitability. This is particularly important due to the fact that the contemporary markets are characterized by sophisticated and diverse preferences of consumers as well as strong competition. Therefore, to meet market demand, firms prefer to offer a product line instead of a single product. In order to decide both on the number and position of products in its product line, the company should understand the way in which consumers value and choose products. For that purpose, a multi-attribute research technique known as conjoint analysis can be used. At the same time, the company should take into account product and pricing strategy of competitors and the possible competitors' reactions on its own strategy. For modelling market competition, the concept of the Nash equilibrium appears as an appropriate tool. This paper proposes a model for designing a competitive profit-maximizing product line for a heterogeneous market. Preferences were modelled by a model of partial utilities associated with the corresponding attribute levels, while the logit model is used to transform respondents' preferences into a potential market share. The problem of optimizing the product line was formulated as a nonlinear binary programming model. Proposed model was tested on the previously published conjoint data set, thus confirming its efficiency and applicability.
\end{abstract}

Keywords: competition; conjoint analysis, equilibrium; heterogeneity; preferences; product line

\section{INTRODUCTION}

Defining the product and pricing strategies are the most critical activities for every firm. Customer wants and needs have become so diversified that the need for more customization through the development of product lines has become necessary [1]. This may lead to competitive advantage if customers recognise the difference and have a preference for the difference. It is therefore crucial to elicit the customers' preferences prior to product differentiation.

Over the past few decades, conjoint analysis has emerged as one of the techniques most commonly used to determine customer preferences for products or services. It is widely adopted in many industries, such as economics, tourism, education, health, transport, etc. [2-4]. Conjoint analysis is primarily used to understand how customers value several attributes of product/service based on their assessment of the product or service as a whole. Accordingly, it is often used to optimize products or production lines from a consumer perspective in order to increase market share and thus profit [5-9].

However, to achieve competitive advantage, manufacturers also need to consider the potential reactions of competitors and the effect that this can have on the success of the product. This is especially important when one bears in mind that the introduction of new products is rather expensive, whereas the failure rate of new products is very high. Nash equilibrium is a well-known concept used for modelling and analysing competition. However, most of typical oligopoly models employ the relatively simple demand function which considers how quantity demanded varies with existing products' price, neglecting the influence of all other product attributes on market share.

This paper proposes a model for designing optimal product line design for competitive market characterized with heterogeneous customers' preferences. The proposed optimization model has the objective to maximize the overall firm's profit which depends on consumers' preferences, the costs of production and competitors' possible reactions. Actually, we upgraded a model proposed in [6], in order to obtain more realistic results. We tested the performance of our model and conducted sensitivity analysis to confirm its efficiency and applicability.

The paper is structured as follows. An overview of the literature related to the problem of product line design optimization and problem solving approaches is given in Section 2. In Section 3, a conjoint utility function and a customer's choice model are explained and profitmaximizing product line optimization model, which considers competitive interactions and consumer preferences, is formulated. The proposed model was verified by the use of the previously published conjoint data set, thus confirming the practicality and significance of its implementation. Market equilibrium solution and results of sensitivity analysis are given in Section 4. Finally, the main conclusions are summarized in Section 5.

\section{RELATIONSHIP TO EXISTING RESEARCH}

The problem of optimal product line design has been deeply studied in literature over the past 35 years, but it still remains an interesting topic of research [1, 10-13].

There are two main courses of research, marketing and engineering. On the one hand, researchers strive for balance between the product commonality and the individual product's engineering performance [1]. On the other hand, researchers usually employ simulations or market research techniques to elicit customer preferences towards product characteristics [14-17]. Considerable progress has also been made on coordinating marketing and engineering decisions [18-22].

Among the earliest papers for product line optimization based on preference data from conjoint analysis was [23]. The authors modelled the product line selection problem as a binary programming problem of profit maximization. Modification of the original model and heuristics for solving the model were later proposed in [24]. In [25], a single-stage binary programming formulation is offered to product lines selection based on product attributes and attribute levels. However, the product line design models proposed in [23, 25] do not take into account the costs associated with each of the attribute levels explicitly. Dobson and Kalish [26] suggested a mathematical programming solution for the product line design problem which considers fixed costs. Chen and 
Hausman [27] used a discrete choice model, but their approach is based on the assumption that customers' preferences are homogeneous, and hence cannot be used for designing product lines that meet the heterogeneous preferences of customers.

More recent contributions concerning the problem of product line designs are applications of genetic algorithms [28-30], evolutionary algorithms [31] and particle swarm algorithms [13] to locate near-optimal designs based on conjoint data. Moreover, Kumar and Chatterjee [32] developed a greedy heuristic for solving complex model which considers simultaneous decision on pricing and product line optimization. Recently, in [7] a two-step methodology for designing production lines that optimize the degree of differentiation compared to the commonality among car models in the line is proposed.

Although a certain number of papers deal with optimization of the products or product lines under competitive conditions [33, 34], fewer papers simultaneously consider both consumers and competition. Namely, some authors strived to include competitors' reactions into the process of product design based on conjoint data $[5,6,35]$. Even so, authors have limited their research to homogeneous markets and optimization of a single product, neglecting the fact that in the most highly competitive markets consumer preferences are heterogeneous. However, Steiner [5] examined the market with heterogeneous preferences, treating segments as separate homogeneous markets, thereby limiting the model to optimize a single product. Kuzmanovic and Martic [6] examined a homogenous market and proposed a competitive product line optimisation model based on the averaged preferences. However, averaging consumer preferences often hides the real consumers' needs and wants, causing very serious consequences with long-term negative effects. Identification of heterogeneity of preferences and their incorporation in the model gives a much more accurate and realistic basis for decision making, especially for long-term ones.

\section{MODEL FORMULATION}

The main phases of the methodological framework for designing optimal product line for heterogeneous market are shown in Fig. 1. To specify demand function, we suggest two-phase procedure. In the first phase, the demand parameters are estimated using traditional conjoint technique.

\subsection{Conjoint Utility Function and Customers' Choice Model}

Conjoint experiments involve individuals asked to evaluate various experimentally designed alternatives that are described by their most important characteristics [4].

To model respondents' preferences, a linear additive model of part-worth utilities could be used. Suppose the conjoint experiment which includes $K$ key product attributes, each with $L_{k}$ levels. That part-worth model implies that the overall utility of the product $s$ of firm $j$ for the respondent $i$ can be expressed as follows:

$U_{i j s}=\sum_{k=1}^{K} \sum_{l=1}^{L_{k}} \beta_{i k l} x_{j s k l}+\varepsilon_{i j s}, i=1, \ldots, I, j=1, \ldots, J, s=1, \ldots, S(1)$ $x_{j s k l}$ is a binary variable that equals 1 if product $s$ of the $j^{\text {th }}$ firm contains level $l$ of attribute $k$, otherwise it equals $0 . \varepsilon_{i j s}$ is an error term. Parameters $\beta_{i k l}$ represent respondent $i$ 's utility assigned to the level $l$ of the attribute $k$. These partial utilities are estimated by regression analysis.

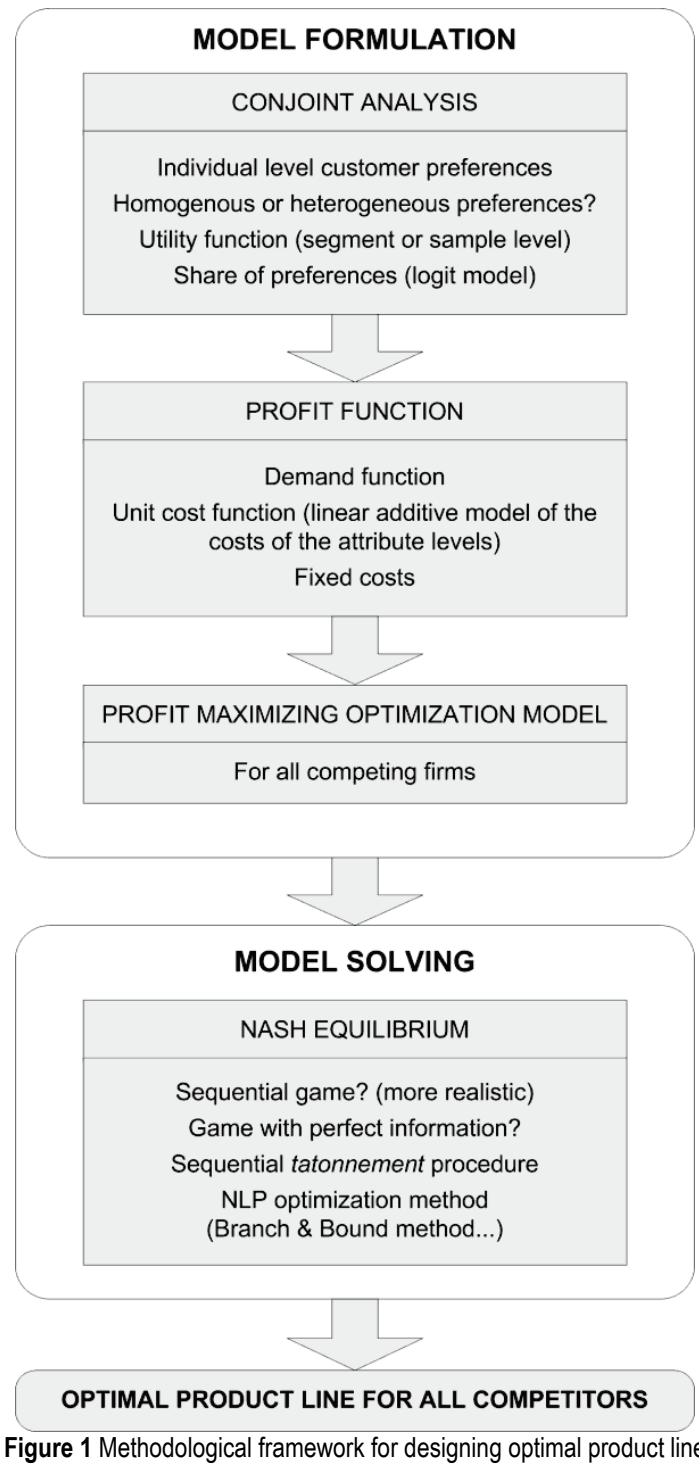

Since part-worths are calculated for each respondent individually, they can be used for a segmentation based on respondents' preferences. Let us assume that $S$ market segments, each with $I_{s}$ individuals are identified. Then the segment level part-worths are $\beta_{s k l}$.

Total utility for a product of the firm $j$ in segment $s$ can be further estimated by inserting the appropriate (segment level) part-worths into Eq. (1):

$\hat{U}_{j s}=\sum_{k=1}^{K} \sum_{l=1}^{L_{k}} \beta_{s k l} x_{j s k l}+\varepsilon_{j s}, s=1, \ldots, S, j=1, \ldots, J$.

Once conjoint utility functions are determined, they should be aggregated in order to determine products market shares in the second phase. For modelling customers' choices and turning them into market share, probabilistic choice rule, i.e. logit model, is used: 


$$
P_{j s}=\frac{\exp \left(\mu \cdot \hat{U}_{j s}\right)}{\sum_{n=1}^{J} \exp \left(\mu \cdot \hat{U}_{n s}\right)}, s=1, \ldots, S, j=1, \ldots, J
$$

where $P_{j s}$ is the probability that the products of the firm $j$ will be chosen by the respondents from the segment $s$ (share of preferences), and $\mu$ is scaling parameter of the logit model $(\mu>0)$ used to fine-tune the results.

\subsection{Profit Function}

One of the most common objectives of any rational firm is to maximize its profit. The total profit of the firm $j$ which offers a line of $S$ products is given by:

$$
\Pi_{j}=\sum_{s=1}^{S}\left(p_{j s}-c_{j s}\right) q_{j s}-c_{j s}^{f i x}, \quad j=1, \ldots, J
$$

where $p_{j s}$ is the price of firm $j$ 's product $s ; c_{j s}$ and $c_{j s}^{f i x}$ are firm $j$ 's variable and fixed unit cost of producing product $s$, respectively. $q_{j s}$ is demand for the product $s$ of the firm $j$ on the market with total market size of $Q$ :

$$
q_{j s}=\frac{I_{s}}{I} Q \cdot P_{j s}, j=1, \ldots, J, s=1, \ldots, S
$$

Following $[5,6]$ we assume that the unit cost function is a linear additive model of the costs assigned to the levels of each of non-price attributes. Let us assume that the product selling price is labelled as $K^{\text {th }}$ attribute. Thus, if $c_{j k l}$ denotes the cost associated to the firm $j^{\text {th }}$ level $l$ of the attribute $k$, the unit production costs of firm $j$ 's product $s$ can be expressed as follows:

$$
c_{j s}=c_{j s}\left(\boldsymbol{x}_{j s}\right)=\sum_{k=1}^{K-1} \sum_{l=1}^{L} c_{j k l} x_{j s k l}, s=1, \ldots, S, j=1, \ldots, J
$$

\subsection{Profit-Maximizing Product Line Optimization Model}

Objective function that maximizes the overall profit of the firm $j$ that offers $S$ products is given by:

$$
\max _{\boldsymbol{x}_{j}} \Pi_{j}=\sum_{s=1}^{S}\left(p_{j s}-c_{j s}\left(\boldsymbol{x}_{j s}\right)\right) Q_{s} \frac{\exp \left(\mu \cdot \hat{U}_{j s}\right)}{\sum_{n=1}^{J} \exp \left(\mu \cdot \hat{U}_{n s}\right)}-\sum_{s=1}^{S} c_{j s}^{f i x}
$$

where $\hat{U}_{j s}$ is total utility of the product $s$ of the firm $j$, estimated by using Eq. (2). All products in the product line contain one level of each attribute:

$$
\sum_{l=1}^{L_{k}} x_{j s k l}=1, s=1, \ldots, S, k=1, \ldots, K
$$

A rational firm will set unit selling price higher than the cost of production, thus providing a positive profit:

$$
p_{j s}-c_{j s}\left(\boldsymbol{x}_{j s}\right)>0, j=1, \ldots, J, s=1, \ldots, S
$$

To ensure that the products of the firm $j$ differ in at least $\alpha_{j}$ attribute levels, the following condition should be applied:

$$
\sum_{k \in K_{j}} \sum_{l=1}^{L_{k}}\left|x_{j s k l}-x_{j s^{\prime} k l}\right| \geq \alpha_{j}, K_{j}{ }^{\prime} \subset K, s, s^{\prime} \in S, s \neq s^{\prime}
$$

The presence of a specific attribute level in the product configuration is given by constraint:

$$
x_{j s k l} \in\{0,1\}, s=1, \ldots, S, k=1, \ldots, K, l=1, \ldots, L_{k}
$$

Additionally, if one of product attributes is the price, for example attribute $K$, it should be ensured that its level corresponds to the selling price of the given product $p_{j s}$.

In model (7)-(11) the optimal product line could be obtained through the manipulation of the attribute levels. Solution for all of the competing firms simultaneously is known as Nash equilibrium. Set of product line designs, one for each firm, is optimal (i.e. Nash equilibrium is reached) if no firm has interest to deviate from its own product line strategy unilaterally [6].

To determine Nash equilibrium we used an iterative process of adjustment, introduced in $[35,36]$ and used by some other authors to determine both Nash equilibrium in simultaneous product-price game $[6,37]$ and StackelbergNash equilibrium in sequential game [34]. In each iteration of the adjustment process, the branch and bound method was used for optimization.

\begin{tabular}{|c|c|c|c|c|c|c|}
\hline \multirow{2}{*}{ Attributes } & \multirow{2}{*}{ 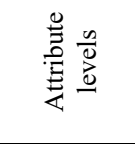 } & \multirow{2}{*}{ ن } & \multicolumn{3}{|c|}{ Part-worth utilities } & \multirow[b]{2}{*}{$\begin{array}{c}\text { Costs* } \\
(€)\end{array}$} \\
\hline & & & Aggr. & $\begin{array}{c}\text { Segm. } 1 \\
(60 \%)\end{array}$ & \begin{tabular}{|c|} 
Segm. 2 \\
$(40 \%)$
\end{tabular} & \\
\hline \multirow{3}{*}{ Manufacturer } & F1 & 1 & 1,56 & 1,99 & 1,03 & $100 * *$ \\
\hline & F2 & 2 & 1,79 & 1,49 & 2,14 & $100 * *$ \\
\hline & F3 & 3 & 0,55 & 0,52 & 0,93 & $100 * *$ \\
\hline \multirow{3}{*}{ Price } & $320 €$ & 1 & 2,35 & 2,89 & 2,04 & 1 \\
\hline & $400 €$ & 2 & 1,94 & 1,92 & 1,99 & 1 \\
\hline & $550 €$ & 3 & $-0,38$ & $-0,8$ & $-0,27$ & 1 \\
\hline \multirow{3}{*}{$\begin{array}{c}\text { Printing } \\
\text { speed } \\
\text { (pg/min) }\end{array}$} & 8 & 1 & 0,42 & 0,19 & 0,79 & 0 \\
\hline & 12 & 2 & 1,20 & 1,54 & 1,1 & 20 \\
\hline & 16 & 3 & 2,29 & 2,27 & 2,49 & 40 \\
\hline \multirow{3}{*}{$\begin{array}{c}\text { Max number } \\
\text { of pages }\end{array}$} & $<5000$ & 1 & $-1,17$ & $-0,97$ & $-1,58$ & 0 \\
\hline & $5000-7000$ & 2 & 2,13 & 1,89 & 2,28 & 20 \\
\hline & $>7000$ & 3 & 2,96 & 2,11 & 3,18 & 60 \\
\hline \multirow{2}{*}{$\begin{array}{c}\text { Double-sided } \\
\text { printing }\end{array}$} & Yes & 1 & 2,20 & 2,18 & 2,24 & 60 \\
\hline & No & 2 & 0,45 & 0,49 & 0,34 & 0 \\
\hline
\end{tabular}

\section{AN ILLUSTRATION \\ 4.1 Conjoint Data}

The proposed model will be tested on a conjoint data set for the printer characteristics, published in [38]. Both averaged and segment level part-worth utilities of all the attribute levels are given in Tab. 1. The costs of production are hypothetical because they are not listed in [38].

Table 1 Conjoint data set [35]

* Hypothetical costs, assumed to be equal for all firms

** The costs of production printers with basic characteristics (printers

containing the lowest levels of ordinal non-price attributes)

Fig. 2 illustrates the differences in the preferences of customers across the two segments towards five key 
attributes, resulting from the corresponding part-worths shown in Tab. 1.

As with most product categories, customers are pricesensitive, and they express higher utilities for lower prices. However, customers of segment 1 are more sensitive to price changes than the customers of segment 2 . On the other hand, the economy of printer exploitation has the greatest impact on the choice of customers from segment 2. The least important attribute for all customers is Manufacturer.

For the given part-worths, optimal printer for both segments has the following characteristics: double-side printer with printing speed of 16 pages per minute and capability to print more than 7000 pages, that costs $320 €$

By choosing to produce a unique printer (those with optimal characteristics) for the whole market, the firms' market shares and profits will be somewhat different precisely because of the respondents' preferences towards certain printer brands (see Tab. 2, Scenario T0). Later on it will be shown that the selection of an optimal product without considering possible competitors' reactions, can lead to a suboptimal solution.

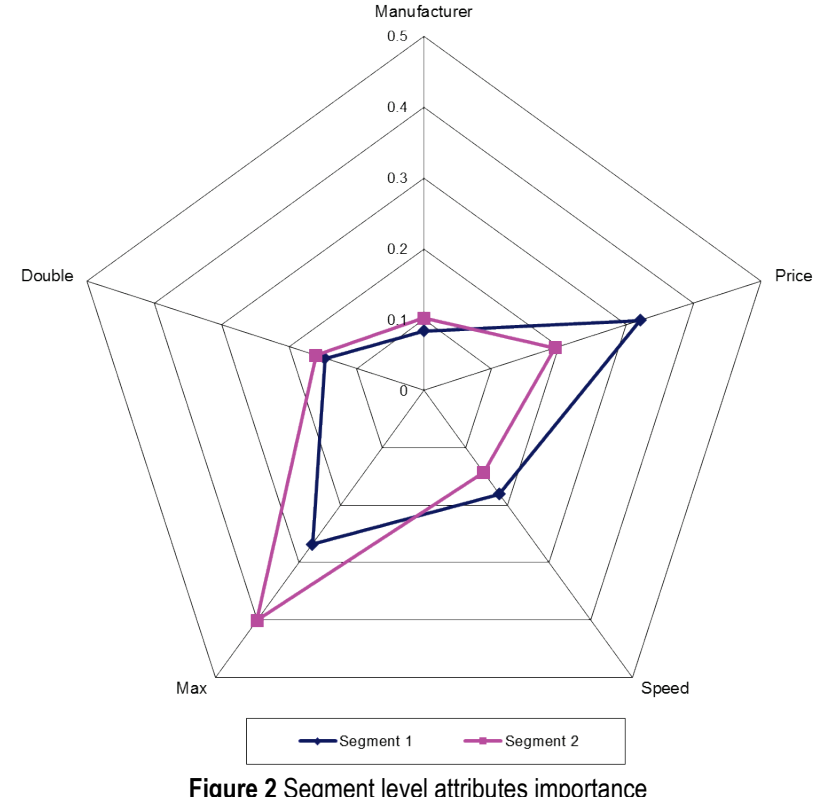

Figure 2 Segment level attributes importance

Table 2 Solution of the Scenario TO

\begin{tabular}{|c|c|c|c|c|c|c|c|c|c|c|c|}
\hline Scenario & Firm & Product line & & Attr & ute & vels & & $\begin{array}{l}\text { Profit per } \\
\text { product* }\end{array}$ & $\begin{array}{l}\text { Overall } \\
\text { profit* }\end{array}$ & $\begin{array}{c}\text { Market share } \\
\text { (per product), \% }\end{array}$ & $\begin{array}{l}\text { Overall market } \\
\text { share, } \%\end{array}$ \\
\hline \multirow{6}{*}{ T0 } & \multirow{2}{*}{ F1 } & $\mathrm{S} 11$ & 1 & 1 & 3 & 3 & 1 & 1633,58 & \multirow{2}{*}{2240,97} & 27,23 & \multirow{2}{*}{37,35} \\
\hline & & $\mathrm{S} 12$ & 1 & 1 & 3 & 3 & 1 & 607,39 & & 10,12 & \\
\hline & \multirow{2}{*}{$\mathrm{F} 2$} & S21 & 2 & 1 & 3 & 3 & 1 & 990,82 & \multirow{2}{*}{2833,84} & 16,51 & \multirow{2}{*}{47,23} \\
\hline & & $\mathrm{S} 22$ & 2 & 1 & 3 & 3 & 1 & 1843,03 & & 30,72 & \\
\hline & \multirow{2}{*}{ F3 } & $\mathrm{S} 31$ & 3 & 1 & 3 & 3 & 1 & 375,60 & \multirow{2}{*}{925,19} & 6,26 & \multirow{2}{*}{15,42} \\
\hline & & $\mathrm{S} 32$ & 3 & 1 & 3 & 3 & 1 & 549,59 & & 9,16 & \\
\hline
\end{tabular}

$*$ in euros $\times 10^{3}$

Table 3 Scenario T1 -Nash equilibrium solution

\begin{tabular}{|c|c|c|c|c|c|c|c|c|c|c|c|}
\hline Scenario & Firm & Product line & & $\operatorname{ttr}$ & ute & ve & & Profit per product* & $\begin{array}{l}\text { Overall } \\
\text { profit* }\end{array}$ & $\begin{array}{c}\text { Market share } \\
\text { (per product), \% }\end{array}$ & $\begin{array}{c}\text { Overall market } \\
\text { share, } \%\end{array}$ \\
\hline \multirow{6}{*}{$\mathrm{T} 1$} & \multirow{2}{*}{ F1 } & S11 & 1 & 1 & 3 & 2 & 1 & 3267,16 & \multirow{2}{*}{4400,95} & 32,67 & \multirow{2}{*}{40,77} \\
\hline & & S12 & 1 & 2 & 3 & 3 & 1 & 1133,79 & & 8,10 & \\
\hline & \multirow{2}{*}{$\mathrm{F} 2$} & $\mathrm{~S} 21$ & 2 & 1 & 3 & 2 & 1 & 1981,63 & \multirow{2}{*}{5421,95} & 19,82 & \multirow{2}{*}{44,39} \\
\hline & & S22 & 2 & 2 & 3 & 3 & 1 & 3440,32 & & 24,57 & \\
\hline & \multirow{2}{*}{ F3 } & $\mathrm{S} 31$ & 3 & 1 & 3 & 2 & 1 & 751,20 & \multirow{2}{*}{1777,10} & 7,51 & \multirow{2}{*}{14,84} \\
\hline & & S32 & 3 & 2 & 3 & 3 & 1 & 1025,89 & & 7,33 & \\
\hline
\end{tabular}

\subsection{The Market Equilibrium}

Since two segments of different preferences have been identified, we tested the model proposed in Section 3, assuming that there are at most two products in the production line. Equilibrium analysis and simulations were performed assuming that the total demand in the market is 10000 products, of which 6000 is demanded in segment 1 , and the remaining 4000 in segment 2 .

We also assumed that products in the product line must differ in at least two attributes. This has been done to eliminate the possibility that two products of the same firm and with identical characteristics are sold at different prices, or that products of different performances are sold at the same price.

Optimization results obtained by using data from Tab. 1 and sequential adjustment procedure are shown in Tab. 3 (scenario T1). Initial feasible solution is randomly chosen, and Nash equilibrium was achieved in the third iteration. In the equilibrium, profits achieved by all of three firms are higher than those in the scenario T0 where potential reactions of competitors were neglected. The profit of firms F1, F2 and F3 amounted to $4400,95 \times 10^{3} €$, $5421,95 \times 10^{3} €$ and $1777,10 \times 10^{3} €$, respectively. For each of these firms, it is optimal to manufacture two types of printers, one for both of identified segments (product lines consists of two printers, $\mathrm{S}_{j 1}$ and $\mathrm{S}_{j 2}$, where $\left.j=1,2,3\right)$. The functional characteristics of both variants of the printer are the same in all three firms. What distinguishes them is precisely their manufacturer, i.e. brand.

However, the price of the printers with best performance increased compared to $\mathrm{T} 0$ scenario. This is in line with the assumption that differentiation provides an opportunity for firms to prevent a price cut to the lowest level.

\subsection{Sensitivity Analysis}

For a detailed testing of the proposed model, a sensitivity analysis was conducted. More precisely, to confirm efficiency of the model, the effects of changing the assumptions and some parameters on the results were examined. We tested the changes in the cost structure and initial solution that play a great role in shaping equilibrium. 
1. The scenario where the costs of production of the printer with basic characteristics differ across competitors was simulated. The simulation results showed that changing the values of these parameters influenced neither equilibrium strategy (the product characteristics and price remained the same) nor market share, but it had influence on total profit, which was expected. The profit was higher when costs decreased and lower otherwise.

2. The scenario where the costs assigned to the attribute levels differ across competitors was simulated (Scenario T2, see Tab. 4). The costs assigned to level 2 of the attribute Speed for the firm F1 are lower, while for the firms F2 and F3 lower costs are assigned to level 3 of the attribute Max. To obtain equilibrium, we used as initial solution that equilibrium derived in case of scenario $\mathrm{T} 1$. This equilibrium showed to be the same as in case of scenario $\mathrm{T} 2$ : the product and price strategies remain the same, so as the profit of firm F1, while profits of firms F2 and F3 slightly differ. Namely, the profit of firm F2 rises from $5421,95 \times 10^{3} €$ to $5913,43 \times 10^{3} €$, and that of firm F3 rises from $1777,10 \times 10^{3} €$ to $1923,65 \times 10^{3} €$. The reason is the decrease of attribute costs that participate in product equilibrium strategy. Profit of firm F1 is the same because the level whose cost is lower does not influence the change of firm F1's strategy, hence it does not determine optimal solution.

The next step was to change initial solution. We used randomly generated initial product configuration, and in the second iteration, different equilibrium was determined. In this equilibrium, strategies of firms $\mathrm{F} 2$ and $\mathrm{F} 3$ rest the same, while the one of firm F1 is changed. Profit of firm F1 is lower, but it is higher in firms F2 and F3; the same holds for their market shares (see Tab. 5). Hence, firm F1 should not use this equilibrium solution. Note that the profit of all three firms in case of both equilibria is higher than in scenario $\mathrm{T} 0$.

Table 4 Production costs assigned to the attribute levels: scenario T2 and scenario T4

\begin{tabular}{|c|c|c|c|c|c|c|c|}
\hline \multirow{3}{*}{ Attributes } & \multirow{3}{*}{ Attribute levels } & \multicolumn{6}{|c|}{ Cost* $(€)$} \\
\hline & & \multicolumn{3}{|c|}{ Scenario T2 } & \multicolumn{3}{|c|}{ Scenario T4 } \\
\hline & & F1 & F2 & F3 & $\mathrm{F} 1$ & F2 & F3 \\
\hline \multirow{3}{*}{ Printing speed } & $8 \mathrm{pg} / \mathrm{min}$ & 0 & 0 & 0 & 0 & 0 & 0 \\
\hline & $12 \mathrm{pg} / \mathrm{min}$ & 10 & 20 & 20 & 20 & 20 & 20 \\
\hline & $16 \mathrm{pg} / \mathrm{min}$ & 40 & 40 & 40 & 40 & 40 & 40 \\
\hline \multirow{3}{*}{ Max number of pages } & $<5000$ & 0 & 0 & 0 & 0 & 0 & 0 \\
\hline & $5000-7000$ & 20 & 20 & 20 & 20 & 20 & 10 \\
\hline & $>7000$ & 60 & 40 & 40 & 60 & 50 & 40 \\
\hline \multirow{2}{*}{ Double-sided printing } & Yes & 60 & 60 & 60 & 60 & 60 & 60 \\
\hline & No & 0 & 0 & 0 & 0 & 0 & 0 \\
\hline Costs of production basic printers & & 100 & 100 & 100 & 100 & 100 & 100 \\
\hline
\end{tabular}

$*$ in euros $\times 10^{3}$

Table 5 Scenario T2 -Nash equilibrium solution

\begin{tabular}{|c|c|c|c|c|c|c|c|c|c|c|}
\hline Firm & Product line & \multicolumn{5}{|c|}{ Attribute levels } & Profit per product* & Overall profit* & $\begin{array}{c}\text { Market share } \\
\text { (per product), \% }\end{array}$ & $\begin{array}{l}\text { Overall market } \\
\text { share, } \%\end{array}$ \\
\hline \multirow{2}{*}{$\mathrm{F} 1$} & $\mathrm{~S} 11$ & 1 & 2 & 3 & 2 & 1 & 3368,13 & \multirow[b]{2}{*}{3772,53} & 18,71 & \multirow{2}{*}{21,09} \\
\hline & $\mathrm{S} 12$ & 1 & 2 & 2 & 3 & 1 & 404,39 & & 2,38 & \\
\hline \multirow{2}{*}{$\mathrm{F} 2$} & $\mathrm{~S} 21$ & 2 & 1 & 3 & 2 & 1 & 2993,88 & \multirow[b]{2}{*}{7630,62} & 29,94 & \multirow{2}{*}{58,92} \\
\hline & $\mathrm{S} 22$ & 2 & 2 & 3 & 3 & 1 & 4636,73 & & 28,98 & \\
\hline \multirow{2}{*}{ F3 } & S31 & 3 & 1 & 3 & 2 & 1 & 1134,93 & \multirow[b]{2}{*}{2517,59} & 11,35 & \multirow{2}{*}{19,99} \\
\hline & S32 & 3 & 2 & 3 & 3 & 1 & 1382,66 & & 8,64 & \\
\hline
\end{tabular}

$*$ in euros $\times 10^{3}$

Table 6 Scenario T3 -Nash equilibrium solution

\begin{tabular}{|c|c|c|c|c|c|c|c|c|c|c|}
\hline Firm & Product line & \multicolumn{5}{|c|}{ Attribute levels } & Profit per product* & Overall profit* & $\begin{array}{c}\text { Market share } \\
\text { (per product), \% }\end{array}$ & $\begin{array}{l}\text { Overall market } \\
\text { Share, \% }\end{array}$ \\
\hline \multirow{2}{*}{ F1 } & S11 & 1 & 2 & 3 & 2 & 1 & 3368,13 & \multirow[b]{2}{*}{4501,92} & 18,71 & \multirow{2}{*}{26,81} \\
\hline & S12 & 1 & 2 & 3 & 3 & 1 & 1133,79 & & 8,10 & \\
\hline \multirow{2}{*}{$\mathrm{F} 2$} & $\mathrm{~S} 21$ & 2 & 1 & 3 & 2 & 1 & 2993,88 & \multirow[b]{2}{*}{6434,20} & 29,94 & \multirow{2}{*}{54,51} \\
\hline & S22 & 2 & 2 & 3 & 3 & 1 & 3440,32 & & 24,57 & \\
\hline \multirow{2}{*}{ F3 } & S31 & 3 & 1 & 3 & 2 & 1 & 1134,93 & \multirow[b]{2}{*}{2160,82} & 11,35 & \multirow{2}{*}{18,68} \\
\hline & S32 & 3 & 2 & 3 & 3 & 1 & 1025,89 & & 7,33 & \\
\hline
\end{tabular}

$*$ in euros $\times 10^{3}$

3. The assumption that firms do not necessarily have to produce different products for isolated segments (Scenario T3) was tested. We supposed that $\alpha_{j}=0, j=1,2$ (see Eq. (11)). The model was tested for different initial solutions, and we always obtained the same equilibrium at most in three iterations. The optimal solution in the case when the initial solution was the same product for both segments is given in Tab. 6 .

4. In case when firms do not necessarily have to produce different products for isolated segments, the change of costs assigned to some attribute levels was simulated (Tab. 4, Scenario T4). More precisely, the influence of costs decrease assigned to some levels of the most important attributes for firms F2 and F3 was analysed. The result got was the same product-price strategy as in case of scenario T3; the only difference is in slightly higher profit of firms F2 and F3. The reason is the cost decrease assigned to the optimal products characteristics.

Analysing the previous scenarios, the following conclusions can be summed up:

- In each of the previous scenarios (where the proposed model was applied), the solution was better than in case when possible reactions of the competitors were not considered (Scenario T0). 
- It is confirmed that the proposed model is efficient even in case when cost parameters are changed. The change of costs assigned to the attributes does not influence significantly the change of optimal product strategy, but it does influence the total profit. We also confirmed that optimal product profiles are far less sensitive to absolute cost levels than to the relative magnitude across cost levels. This is in line with $[5$, $6]$.

It is showed that changing the initial configuration can, in some cases, influence the optimal solution of the proposed model, which is also in accordance with observations of some other authors [35]. Namely, depending on the initial product configuration, it is possible to obtain different solution, if there are multiple equilibria. However, even in that case, using manager's intuition, it is possible to eliminate those equilibria that are less efficient or less probable.

\subsection{Suitability and Implications of the Proposed Model}

We showed and proved suitability of the proposed model to design a profit-maximizing product line for heterogeneous market by simulating different scenarios. Below, a summary overview of advantages and weaknesses of our approach is given.

Advantages:

- In designing an optimal product line, our approach considers both the possible reactions of the competitors and potential heterogeneity of customers' preferences.

- Conjoint data (importance of the product attributes) determined in the first phase of the proposed approach, can direct managers to recognize not only the strategies appropriate for them, but also those that may be used by the competitors.

- The proposed approach gives numerous useful information regarding customers' preferences and the options to simulate competitors' rational decisions in the given circumstances.

- Averaging consumer preferences often masks the real needs and desires of consumers, causing very serious consequences with long-term negative effects. Identification of heterogeneity of preferences and their inclusion in the analysis using the proposed model, gives a much more accurate and realistic basis for decision making, especially for long-term ones.

- The model we proposed is general and widely applicable, and it is not sensitive to the parameter changes. It can be applied to markets with a larger number of firms. The model also can be adapted to perform optimization of either the price or a subset of the selected attributes. In that case, the utilities of the remaining attributes are considered to be fixed. That can be done for each firm, whereby the number of variables need not be the same across the firms. This feature of the proposed model can be particularly important when making short-term decisions, and to conduct what-if analysis.

To solve the model, it is possible to use some of the widely available software. In this paper, we applied Excel Solver.
- The proposed approach enables a simple application of sensitivity analysis and what-if analysis.

Weaknesses:

To apply the proposed approach, it is essential to conduct a conjoint analysis beforehand. Although this can be regarded as a disadvantage, there are several benefits and some of them are listed earlier. In practice, firms often conduct conjoint analysis to elicit customer preferences without further product optimization. Hence, applying our model to the already collected conjoint data gives a much better basis for decision-making.

- There is a problem of collecting accurate data on the unit cost of product attributes. Particularly difficult is to identify the costs of competing firms.

- $\quad$ It requires knowledge of the optimization software.

Bearing in mind the above mentioned advantages of the model, it is clear that it can help managers to determine their product-price strategy and thus business strategy as well. Moreover, the results of the model simulations provide a clearer understanding of market competition and the possible rational strategies of competitors.

\section{CONCLUSIONS}

In a highly competitive business environment, firms are focused on maximizing their market share and profits through meeting the demanding wants and needs of specific groups of customers. Therefore, it is crucial for all firms to carefully define product and pricing strategies and to distinguish their offer from the similar ones, both from the offering of competitors and firm's own product offering. This could be done through product differentiation. Through the product line, the firm can tailor its offer to meet diverse wants of individual customers and segments, thereby maximizing its own profit.

Bearing the foregoing in mind, in this paper, a competitive product line optimization model for a market with heterogeneous customers' preferences is proposed. The model is based on individual customers' preferences and cost data, but considers competitive interactions in the market.

To elicit individual customers' preferences and to identify specific market segments, research technique conjoint analysis was proposed. Conjoint analysis enables to determine product attributes that are relevant to specific customer or market segment, as well as customers' sensitivity to changes in attribute values.

Customer preferences were modelled by a linear additive model of partial utilities associated with the corresponding product characteristics, i.e. attribute levels. Customer choices are modelled by the use of logit model. The problem of product line design optimization is formulated as a nonlinear binary programming model that maximizes total profit. In order to find out solution of the model, equilibrium concept was employed. To calculate Nash's equilibrium and choose the optimal product line design, a sequential iterative adjustment procedure was used. In each iteration of this procedure, a branch and bound method was employed to solve the optimization problem. 
The proposed model was tested and its performances are compared with the performances of the scenario where potential competitive reactions are neglected. Furthermore, sensitivity analysis confirmed the model efficiency and applicability in practice.

\section{REFERENCES}

[1] Tsafarakis, S., Saridakis, C., Baltas, G., \& Matsatsinis, N. (2013). Hybrid particle swarm optimization with mutation for optimizing industrial product lines: An application to a mixed solution space considering both discrete and continuous design variables. Industrial Marketing Management, 42(4), 496-506.

https://doi.org/10.1016/j.indmarman.2013.03.002

[2] Kuzmanovic, M., Savic, G., Gusavac, B. A., MakajicNikolic, D., \& Panic, B. (2013). A Conjoint-based approach to student evaluations of teaching performance. Expert Systems with Applications, 40(10), 4083-4089.

https://doi.org/10.1016/j.eswa.2013.01.039

[3] Webb, E. J., Meads, D., Eskyte, I., King, N., Dracup, N., Chataway, J., \& Manzano, A. (2018). A Systematic Review of Discrete-Choice Experiments and Conjoint Analysis Studies in People with Multiple Sclerosis. The PatientPatient-Centered Outcomes Research, 1-12. https://doi.org/10.1007/s40271-017-0296-y

[4] Vukic, M., Kuzmanovic, M., \& Kostic Stankovic, M. (2015). Understanding the heterogeneity of Generation Y's preferences for travelling: A conjoint analysis approach. International Journal of Tourism Research, 17(5), 482-491. https://doi.org/10.1002/jtr.2015

[5] Steiner, W. J. (2010). A Stackelberg-Nash model for new product design. OR spectrum, 32(1), 21-48. https://doi.org/10.1007/s00291-008-0137-4

[6] Kuzmanovic, M. \& Martic, M. (2012). An approach to competitive product line design using conjoint data. Expert Systems with Applications, 39(8), 7262-7269. https://doi.org/10.1016/j.eswa.2012.01.097

[7] Saridakis, C., Tsafarakis, S., Delias, P., Baltas, G., \& Matsatsinis, N. (2015). Optimizing differentiation and commonality levels among models in car line-ups: An empirical application of a nature-inspired heuristic mechanism. Expert Systems with Applications, 42(5), 23232335. https://doi.org/10.1016/j.eswa.2014.11.008

[8] Huang, D., Lin, Z. K., \& Wei, W. (2018). Optimal production planning with capacity reservation and convex capacity costs. Advances in Production Engineering \& Management, 13(1), 31-43. https://doi.org/10.14743/apem2018.1.271

[9] Liu, Y. F., \& Zhang, Q. S. (2018). Multi-objective production planning model for equipment manufacturing enterprises with multiple uncertainties in demand. Advances in Production Engineering \& Management, 13(4), 429-441. https://doi.org/10.14743/apem2018.4.301

[10] Lancaster, K. (1990). The economics of product variety: A survey. Marketing science, 9(3), 189-206. https://doi.org/10.1287/mksc.9.3.189

[11] Krishnan, V. \& Ulrich, K. T. (2001). Product development decisions: A review of the literature. Management Science, 47(1), 1-21. https://doi.org/10.1287/mnsc.47.1.1.10668

[12] Ramdas, K. (2003). Managing product variety: An integrative review and research directions. Production and Operations Management, 12(1), 79-101. https://doi.org/10.1111/j.1937-5956.2003.tb00199.x

[13] Tsafarakis, S. \& Matsatsinis, N. (2010). Designing optimal products: Algorithms and systems. In Marketing Intelligent Systems Using Soft Computing (pp. 295-336). Springer, Berlin, Heidelberg. https://doi.org/10.1007/978-3-642-15606-9_19
[14] Luo, L., Kannan, P. K., \& Ratchford, B. T. (2008). Incorporating subjective characteristics in product design and evaluations. Journal of Marketing Research, 45(2), 182194. https://doi.org/10.1509/jmkr.45.2.182

[15] Kannan, P. K., Pope, B. K., \& Jain, S. (2009). Practice prize winner-Pricing digital content product lines: A model and application for the National Academies Press. Marketing Science, 28(4), 620-636. https://doi.org/10.1287/mksc.1080.0481

[16] Kumar, D., Chen, W., \& Simpson, T. W. (2009). A marketdriven approach to the design of platform-based product families. International Journal of Production Research, 47(1), 71-104. https://doi.org/10.1080/00207540701393171

[17] Aydin, R., Kwong, C. K., Ji, P., \& Law, H. M. C. (2014). Market demand estimation for new product development by using fuzzy modeling and discrete choice analysis. Neurocomputing, 142, 136-146. https://doi.org/10.1016/j.neucom.2014.01.051

[18] Eliashberg, J. \& Steinberg, R. (1993). Marketing-production joint decision-making. Handbooks in operations research and management science, 5, 827-880. https://doi.org/10.1016/S0927-0507(05)80041-6

[19] Luo, L. (2011). Product line design for consumer durables: an integrated marketing and engineering approach. Journal of Marketing Research, 48(1), 128-139. https://doi.org/10.1509/jmkr.48.1.128

[20] Michalek, J. J., Ebbes, P., Adigüzel, F., Feinberg, F. M., \& Papalambros, P. Y. (2011). Enhancing marketing with engineering: Optimal product line design for heterogeneous markets. International Journal of Research in Marketing, 28(1), 1-12. https://doi.org/10.1016/j.jiresmar.2010.08.001

[21] Goswami, M., Daultani, Y., \& Tiwari, M. K. (2017). An integrated framework for product line design for modular products: product attribute and functionality-driven perspective. International Journal of Production Research, 55(13), 3862-3885. https://doi.org/10.1080/00207543.2017.1314039

[22] Márkus, A. \& Váncza, J. (2001, June). Product line design with customer preferences. In International Conference on Industrial, Engineering and Other Applications of Applied Intelligent Systems (pp. 846-855). Springer, Berlin, Heidelberg. https://doi.org/10.1007/3-540-45517-5_93

[23] Green, P. E. \& Krieger, A. M. (1985). Models and heuristics for product line selection. Marketing Science, 4(1), 1-19. https://doi.org/10.1287/mksc.4.1.1

[24] McBride, R. D. \& Zufryden, F. S. (1988). An integer programming approach to the optimal product line selection problem. Marketing Science, 7(2), 126-140. https://doi.org/10.1287/mksc.7.2.126

[25] Kohli, R. \& Sukumar, R. (1990). Heuristics for product-line design using conjoint analysis. Management Science, 36(12), 1464-1478. https://doi.org/10.1287/mnsc.36.12.1464

[26] Dobson, G. \& Kalish, S. (1993). Heuristics for pricing and positioning a product-line using conjoint and cost data. Management Science, 39(2), 160-175. https://doi.org/10.1287/mnsc.39.2.160

[27] Chen, K. D. \& Hausman, W. H. (2000). Mathematical properties of the optimal product line selection problem using choice-based conjoint analysis. Management Science, 46(2), 327-332. https://doi.org/10.1287/mnsc.46.2.327.11931

[28] Alexouda, G. \& Paparrizos, K. (2001). A genetic algorithm approach to the product line design problem using the seller's return criterion: An extensive comparative computational study. European Journal of Operational Research, 134(1), 165-178. https://doi.org/10.1016/S0377-2217(00)00246-0

[29] Steiner, W. \& Hruschka, H. (2003). Genetic algorithms for product design: How well do they really work? International Journal of Market Research, 45(2), 1-13. https://doi.org/10.1177/147078530304500202 
[30] Kwong, C. K., Luo, X. G., \& Tang, J. F. (2011). A multiobjective optimization approach for product line design. IEEE Transactions on Engineering Management, 58(1), 97-108. https://doi.org/10.1109/TEM.2010.2048909

[31] Alexouda, G. (2004). An evolutionary algorithm approach to the share of choices problem in the product line design. Computers \& Operations Research, 31(13), 2215-2229. https://doi.org/10.1016/S0305-0548(03)00173-4

[32] Kumar, S. \& Chatterjee, A. K. (2013). A profit maximizing mathematical model for pricing and selecting optimal product line. Computers \& Industrial Engineering, 64(2), 545-551. https://doi.org/10.1016/j.cie.2012.12.002

[33] Du, G., Jiao, R. J., \& Chen, M. (2014). Joint optimization of product family configuration and scaling design by Stackelberg game. European Journal of Operational Research, 232(2), 330-341. https://doi.org/10.1016/j.ejor.2013.07.021

[34] Liu, X., Du, G., Jiao, R. J., \& Xia, Y. (2017). Product line design considering competition by bilevel optimization of a Stackelberg-Nash game. IISE Transactions, 49(8), 768-780. https://doi.org/10.1080/24725854.2017.1303764

[35] Choi, S. C. \& DeSarbo, W. S. (1993). Game theoretic derivations of competitive strategies in conjoint analysis. Marketing Letters, 4(4), 337-348. https://doi.org/10.1007/BF00994352

[36] Choi, S. C., Desarbo, W. S., \& Harker, P. T. (1992). NoteA numerical approach to deriving long-run equilibrium solutions in spatial positioning models. Management Science, 38(1), 75-86. https://doi.org/10.1287/mnsc.38.1.75

[37] Steiner, W. \& Hruschka, H. (2002). A probabilistic one-step approach to the optimal product line design problem using conjoint and cost data. Review of Marketing Science, 1(4). https://doi.org/10.2139/ssrn.319463

[38] Kuzmanović, M. (2006) Quantitative Methods in Marketing Management: Application of Conjoint Analysis. Yugoslav Operations Research Society, Belgrade, Serbia. (In Serbian).

\section{Contact information:}

Marija KUZMANOVIC, PhD, Associate Professor

University of Belgrade,

Faculty of Organizational Sciences,

Jove llića 154, 11000 Belgrade, Serbia

marija.kuzmanovic@fon.bg.ac.rs

Milan MARTIC, PhD, Full Professor

University of Belgrade,

Faculty of Organizational Sciences,

Jove llića 154, 11000 Belgrade, Serbia

milan@fon.bg.ac.rs

Mirko VUJOŠEVIĆ, PhD, Full Professor

University of Belgrade,

Faculty of Organizational Sciences

Jove llića 154, 11000 Belgrade, Serbia

mirkov@fon.bg.ac.rs 